\title{
Pregnancy: Data, Outcomes, and Treatment Paradigms in Rheumatology
}

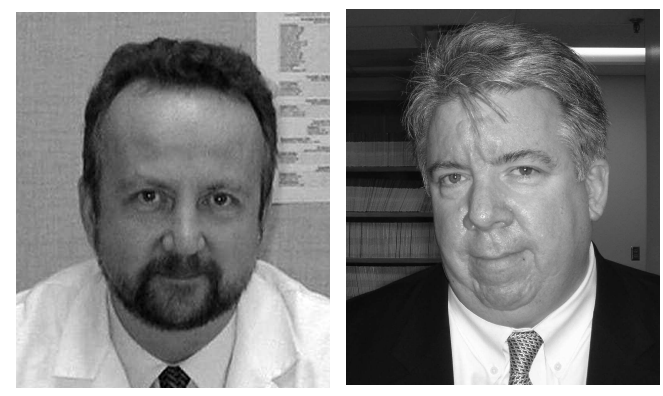

\begin{abstract}
"Doctor, I'm pregnant." Coming from a patient with rheumatoid arthritis (RA), or another systemic inflammatory autoimmune disease, who is taking a handful of medications, these few words reliably quicken the pulse of all rheumatologists. Perhaps the only thing more worrisome is when the patient says "Doctor, I want to become pregnant." In either instance, the apprehensive rheumatologist has to weigh the patient's wishes against the uncertainties inherent in drug use or cessation, and the effects of either on both mother and fetus. The physician's counsel may range from the pure "stop all your rheumatologic medications"; to the positive "wait and the pregnancy will improve your RA"; or the pragmatic "go see a high-risk obstetrician immediately." Often our meager guidance is "let me know when things don't go as planned" or "call me when you're done." The patient who wishes to become pregnant is in a difficult situation. It involves actual discussion between doctor and patient without a solid plan, in an area with a dearth of clinical data from which reasonable decisions could be made. Traditionally, such clinical discussions tended to be as dissatisfying to doctors as they were to patients.
\end{abstract}

Pregnancy has often been treated as if it were an adverse event. It was considered something that interrupted an otherwise carefully planned treatment course for the patient's rheumatologic conditions. Currently, the goal is remission, achieved by using the best possible treatment approaches. The goals of therapy may well be incongruous with the plan for a perfect pregnancy. The lack of data that make this topic so challenging is frustrating but understandable. Some regulatory agencies essentially precluded involvement of pregnant women in any therapeutic research, with the goal being protection of the fetus above all. Since the inception of rheumatology as a discipline, pregnancy remains as complex and mysterious as it is valued and cherished.

Fortunately, things seem to be tangibly improving. Interest in this topic is increasing. The development of new agents that alter the way we treat chronic inflammatory disorders such as RA in women of child-bearing potential has many more physicians and patients talking about pregnancy outcomes and management. People from various disciplines, including rheumatologists, gastroenterologists, dermatologists, obstetricians, and maternal-fetal medicine specialists, teratologists, pediatricians, and patients are coming together to address this crucial topic. For example, the American College of Rheumatology recently convened a reproductive health summit ${ }^{1}$, and similar meetings have taken place internationally, with more being planned ${ }^{2}$. Clearly, a multidisciplinary approach is the best way to insure optimal outcomes. With this interest has come a growing understanding and consensus that the best outcomes for the fetus are closely interwoven with the health of the mother. We know that pregnancy does not induce remission in $80 \%$ of patients with RA. Instead, less than $30 \%$ of patients will achieve remission during pregnancy ${ }^{3}$. Active disease in the mother seems to quite clearly lead to more adverse pregnancy outcomes ${ }^{4}$. Maternal health has been overlooked in the past as clinicians and patients focus on intentional or inadvertent drug exposures as the crucial determinant of fetal outcomes. While more research is needed in this area, regulators have attempted to improve the content and format of prescription drug labeling, especially in pregnancy. The US Food and Drug Administration implemented the Pregnancy and Lactation Labeling Rule (PLLR) in December of 2014 ${ }^{5}$. The "A,B,C,D,X" system established in 1979, which was too simplistic, often misinterpreted, and possibly contributed to poor treatment choices, will be replaced by narratives addressing potential risks and benefits of treatment during pregnancy and lactation. Sections of the PLLR (including Pregnancy, Lactation, and Male and Female reproductive health) will have a risk summary, show all relevant data or state specifically if there are none, add registry information, and include the risks of allowing diseases to go untreated.

There has also been great progress in understanding the immunopathogenesis of pregnancy ${ }^{6,7}$. Normal immune mechanisms are crucial for all aspects of normal pregnancy and delivery, and dysregulation of the immune response underlies many pregnancy-associated disorders, such as preeclampsia and preterm delivery.

See RA disease severity and pregnancy, page 1376

Personal non-commercial use only. The Journal of Rheumatology Copyright @ 2015 . All rights reserved. 
Broadly, there are 2 central questions of greatest relevance to rheumatologists and their patients: (1) what is the effect of maternal disease activity and severity on the fetus, and (2) what are the effects of various therapies on maternal and fetal health? Of course, answers to these key questions require data. Data begets knowledge, knowledge begets understanding, and understanding ultimately begets better clinical decision making.

In this issue of The Journal, Bharti and colleagues present important new data on this topic ${ }^{8}$. The investigators come from Organization of Teratology Information Specialists (OTIS), a group with a long interest and impressive track record on this topic. In this article, the authors show that disease severity in RA, as assessed by the Health Assessment Questionnaire score, was associated with infants that were small for gestational age at birth. The authors postulate, intriguingly but reasonably, that better control of RA early in pregnancy could result in improved outcomes at birth. There are a number of strengths to this work. Prominent among them are the rigorous methods by which this carefully crafted study was conducted and the thorough statistical analyses, such as controlling for important covariates, that allowed them to reach their conclusion. Interestingly, in this study the authors also used remote reporting of RA disease data from the patient; an increasingly important tool in this evolving era of "big data." Further, as anyone who has looked into this area can attest, the recruitment of 440 pregnant patients with RA is very noteworthy.

This study did have some weaknesses as well as opportunities that could have been addressed. For example, there is the potential for some bias in the accrual of patients. As the authors note, volunteer participants in this and similar projects tend to be highly motivated, and better educated and with less disease activity than the general population of patients. Such characteristics may have influenced some of the results, and may affect the ability to generalize to the broader patient population. Of note, $67 \%$ of the patients with RA in this study were taking biologics. No independent assessment was performed of these patients, which is understandable for parsimony of analyses, but it is hoped that in subsequent analyses the authors may address that crucial clinical question.

What does the future hold for this topic? Certainly things appear much more promising than in years past, because accumulating data from new studies should help answer key questions, including those related to fathers ${ }^{9,10}$. While it is unlikely that traditional double-blind placebo-controlled randomized clinical trials will ever focus on pregnant women, relevant data can come from sources such as registries, databanks, and electronic medical records. Rheumatologists and patients should be encouraged toward the collection of data during pregnancy, to help increase the general amount of data available. With more information, patients and rheumatologists can discuss the risks and benefits of treatment options during pregnancy, as they do apart from pregnancy.

Childbirth is one of life's most precious events. In recent years, we have seen the goals of therapy for RA and other autoimmune immune systemic inflammatory disorders continuously pushed, including concepts of treat-to-target, and discussions of what truly defines remission. It is time we also included optimizing outcomes for mother and fetus as an action item in the care of patients.

\section{ARTHUR KAVANAUGH, MD \\ Professor of Medicine, University of California, San Diego; \\ JOHN J. CUSH, MD, \\ Director of Clinical Rheumatology, Baylor Research Institute, \\ Dallas, Texas, USA.}

Address correspondence to Dr. J.J. Cush, Baylor Research Institute, 9900 N. Central Expressway, Suite 550, Dallas, Texas 75231, USA. E-mail: jjcush@gmail.com

\section{REFERENCES}

1. Kavanaugh A, Cush JJ, Ahmed MS, Bermas BL, Chakravarty E, Chambers C, et al. Proceedings from the American College of Rheumatology Reproductive Health Summit: the management of fertility, pregnancy, and lactation in women with autoimmune and systemic inflammatory diseases. Arthritis Care Res 2015;67:313-25.

2. Ostensen M, Andreoli L, Brucato A, Cetin I, Chambers C, Clowse $\mathrm{M}$, et al. State of the art: reproduction and pregnancy in rheumatic diseases. Autoimmun Rev 2015;14:376-86.

3. deMan YA, Dolhain RJ, van de Geijn FE, Willemsen SP, Hazes JM. Disease activity of rheumatoid arthritis during pregnancy: results from a nationwide prospective study. Arthritis Rheum 2008;59:1241-8

4. Lin H, Chen SF, Lin HC, Chen YH. Increased risk of adverse pregnancy outcomes in women with rheumatoid arthritis: a nationwide population-based study. Ann Rheum Dis 2010;69:715-7.

5. Content and format of labeling for human prescription drugs and biological products; requirements for pregnancy and lactation labeling; December 4, 2014, [Internet: US Federal Register Website. Accessed June 8, 2015.] Available from: https://federalregister.gov/a/2014-28241

6. PrabhuDas M, Bonney E, Caron K, Dey S, Erlebacher A, Fazleabas A, et al. Immune mechanisms at the maternal-fetal interface: perspectives and challenges. Nat Immunol 2015;16:328-34.

7. Cerdeira AS, Thadhani R. "Interfering" with preeclampsia. Arthritis Rheum 2015;67:862-4.

8. Bharti B, Lee SJ, Lindsay SP, Wingard DL, Jones KL, Lemus H, et al. Disease severity and pregnancy outcomes in women with rheumatoid arthritis: results from the Organization of Teratology Information Specialists (OTIS) autoimmune diseases in pregnancy project. J Rheumatol 2015;42:1376-82.

9. Rom AL, Wu CS, Olsen J, Kjaergaard H, Jawaheer D, Hetland ML, et al. Fetal growth and preterm birth in children exposed to maternal or paternal rheumatoid arthritis: a nationwide cohort study. Arthritis Rheum 2014;66:3265-73.

10. Wallenius M, Lie E, Daltveit AK, Salvesen KA, Skomsvoll JF, Kalstad S, et al. No excess risks in offspring with paternal preconception exposure to disease-modifying antirheumatic drugs. Arthritis Rheum 2015;67:296-301.

J Rheumatol 2015;42:1357-8; doi:10.3899/jrheum.150566

Personal non-commercial use only. The Journal of Rheumatology Copyright $\odot$ (2015. All rights reserved 